\title{
Setting the absolute threshold of vision
}

\section{Alapakkam P Sampath ${ }^{1 *}$ and Gordon L Fain ${ }^{2}$}

\author{
Addresses: ${ }^{1}$ Department of Physiology and Biophysics, Zilkha Neurogenetic Institute, Keck School of Medicine, University of Southern California, \\ 1501 San Pablo Street, ZNI 435, Los Angeles, CA 90089, USA; ${ }^{2}$ Department of Physiological Science, University of California Los Angeles (UCLA), \\ 3836 Life Sciences Building, Los Angeles, CA 90095, USA \\ *Corresponding author: Alapakkam P Sampath (asampath@usc.edu) \\ FI000 Biology Reports 2009, I:66 (doi:10.34I0/BI-66)
}

The electronic version of this article is the complete one and can be found at: http://FI000.com/Reports/Biology/content/I/66

\begin{abstract}
The performance of sensory systems in many cases is limited by the physical nature of the stimulus. For vision, the quantal nature of light limits detection by dark-adapted observers; only now are we beginning to be aware of the subtleties in the biophysical mechanisms underlying this exquisite sensitivity.
\end{abstract}

\section{Introduction and context}

We have known for over 60 years that a dark-adapted human observer can reliably identify a flash of light activating only a small subset of the photoreceptor cells $[1,2]$. A requirement for such exquisite sensitivity is that the individual rod photoreceptors must be able to produce a reliable signal in the ganglion cells, the cells that provide the output from the retina [3]. Many of the details of how the single-photon response is generated in the rods and how it is processed by retinal interneurons have remained in question. Over the past decade, several important advances have identified and characterized the mechanisms that preserve the single-photon responses amid intrinsic noise in the receptor cells and retinal circuitry.

\section{Major recent advances}

In response to an absorbed photon, rod photoreceptors generate small graded hyperpolarizations on the order of approximately $1 \mathrm{mV}$ [4]. The challenge for retinal processing is to convey this small signal to higher visual centers in the presence of significant receptor noise. Efficient signal transmission through the retina is accomplished by means of a conserved and highly convergent pathway in the mammalian retina called the rod bipolar pathway $[5,6]$. This pathway uses an exclusive rod 'On' bipolar cell and a depolarizing (AII) amacrine cell to boost the single-photon response amplitude and suppress noise, before feeding this signal back into the cone circuitry. The rod signals are then relayed to spiking ganglion cells, which in turn convey this information to the lateral geniculate nucleus and higher visual areas.

Rod phototransduction has received intense study over the past 30 years, but our understanding has deepened considerably with recent advances in mouse genetics that have facilitated the creation of mouse lines with selective perturbations in the signaling cascade. We are now beginning to see in detail how components of the signaling cascade contribute to properties of the singlephoton response. These components include: (a) the role of $\mathrm{Ca}^{2+}$ feedback in the synthesis of cyclic guanosine monophosphate (cGMP), which limits rod noise and speeds the time course of the single-photon response $[7,8]$; (b) the role played by rhodopsin phosphorylation and arrestin binding in the shutoff of the single-photon response [9-11]; and (c) the role played by regulators of G-protein signaling (RGSs) proteins in accelerating the GTPase activity of the G-protein transducin $[12,13]$.

Advances in our understanding of rod synaptic transmission have also revealed specializations for the transmission of the single-photon response. Rod photoreceptors expend considerable energy to maintain a depolarized 
membrane potential in darkness [14] which sets synaptic $\mathrm{Ca}^{2+}$ channels near the steepest point in the relationship between membrane potential and $\mathrm{Ca}^{2+}$ influx [15]. Proteins like calcium-binding protein 4 (CaBP4) [16] have been implicated in the further fine-tuning of this voltage dependence to allow small changes in membrane potential to produce proportionally larger changes in $\mathrm{Ca}^{2+}$ concentration in the presynaptic terminal, which in turn results in a larger change in glutamate release [17].

While the factors that control the size and time course of the single-photon response and of glutamate release have been studied in detail, light detection will ultimately depend on how the system is able to discriminate the single-photon response from noise. Studies of phototransduction have identified two major sources of noise that limit the detection of single photons: the thermal activation of rhodopsin, which generates 'discrete' noise events, and the spontaneous activity of the cGMP phosphodiesterase (PDE), which generates 'continuous' noise $[18,19]$. Either of these forms of noise can produce fluctuations in cGMP that resemble the single-photon response. The key to light detection is therefore the ability of our visual system to discriminate light-driven signals from these two forms of noise. The rod-to-rod bipolar synapse plays a key role in this process. In particular, a threshold-like nonlinearity at this synapse $[20,21]$ is positioned to make an optimum separation of the single-photon response from continuous noise [22]. As shown in Figure 1, this threshold-like nonlinearity acts at every rod-to-rod bipolar synapse to allow only signals that exceed a criterion amplitude to pass through the synapse, so that only the largest responses from the rods can be reliably detected by the bipolars. Rod bipolars are thus able to sum responses from rod photoreceptors in a manner that allows them to preserve the larger single-photon responses while rejecting much of the continuous noise component. Such an operation is believed to improve the signal-tonoise ratio of the single-photon response in rod bipolar cells by more than 300 -fold over what we would expect from a linear combination of rod signals [22].

Figure I. Convergence and threshold-like nonlinearity at the rod-to-rod bipolar synapse

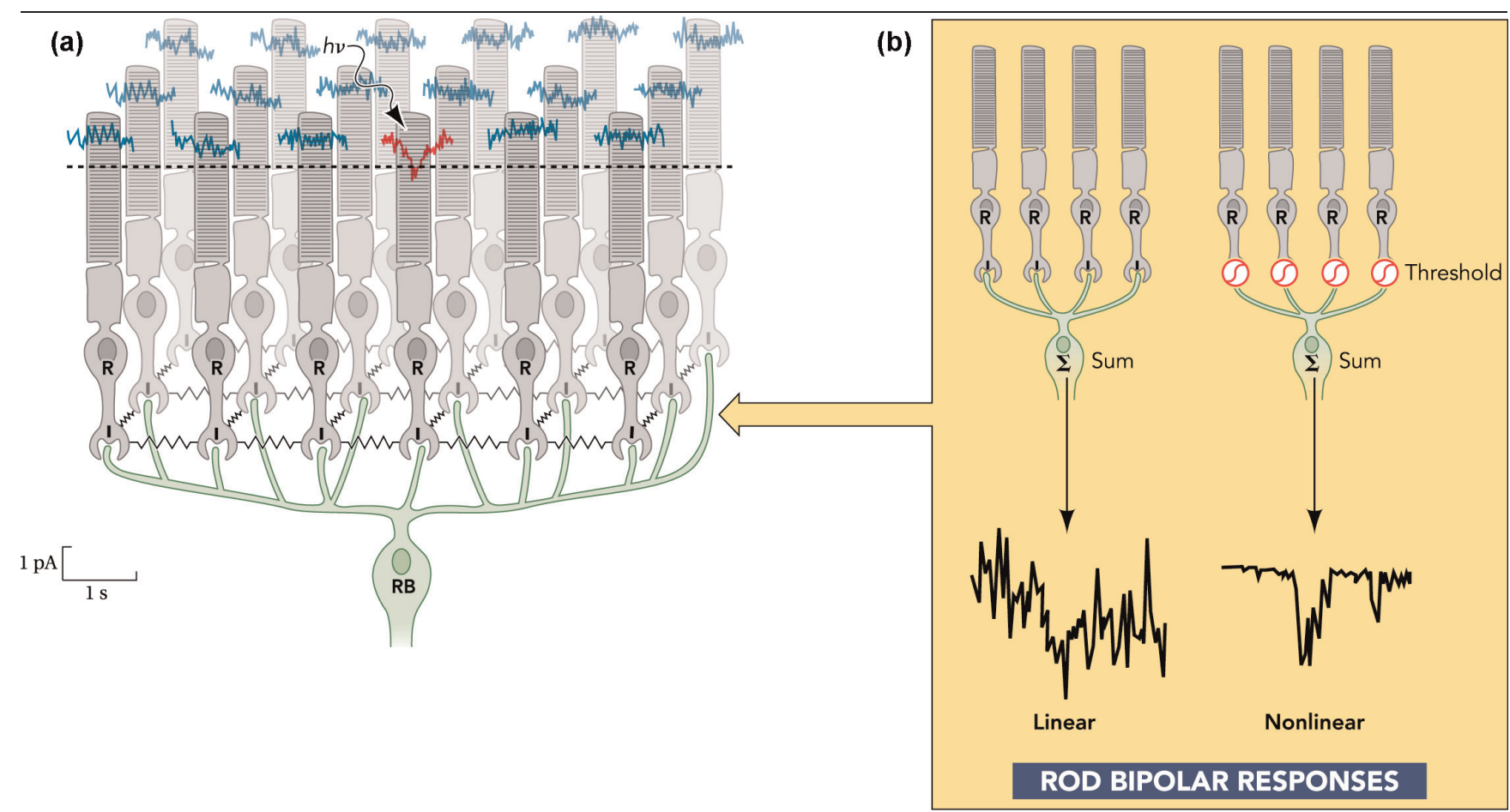

(a) A rod bipolar cell pools inputs from many rods, but near absolute visual threshold, only one rod may absorb a photon (red) while the remaining rods are generating electrical noise (blue). A threshold-like nonlinearity (dashed) improves photon detection at this synapse by retaining responses that exceed threshold (red) in rods most likely absorbing a photon, while discarding responses that do not exceed threshold and that are more likely noise in the remaining rods. (b) Nonlinear signal processing can improve the fidelity of rod signals. If rod outputs from (a) are simply summed, the resulting trace is noisy, but when summed after applying the threshold-like nonlinearity for each rod in (a), the response is easier to discern. R, rod; RB, rod bipolar cells. Reprinted with permission from Physiology [32]. Copyright 2007, The American Physiological Society. 
Mechanistically, this threshold-like nonlinearity is generated by postsynaptic saturation at the rod-to-rod bipolar synapse [23]. This saturation appears not to be attributable to saturation of binding to metabotropic glutamate (mGluR6) receptors on the rod bipolar dendrites but seems instead to occur somewhere within the G-protein cascade that couples mGluR6 to cation channels.

Understanding how the nonlinear threshold is set by rod bipolar cells will ultimately require the elucidation of the mGluR6 signaling pathway in the bipolar dendrites. As shown in Figure 2, glutamate released from rods in darkness is sensed postsynaptically by mGluR6 receptors, which in turn activate $\mathrm{a}_{\mathrm{o}} \mathrm{\alpha}$-containing G-protein.

Figure 2. Structure and signal transfer at the rod-to-rod bipolar synapse

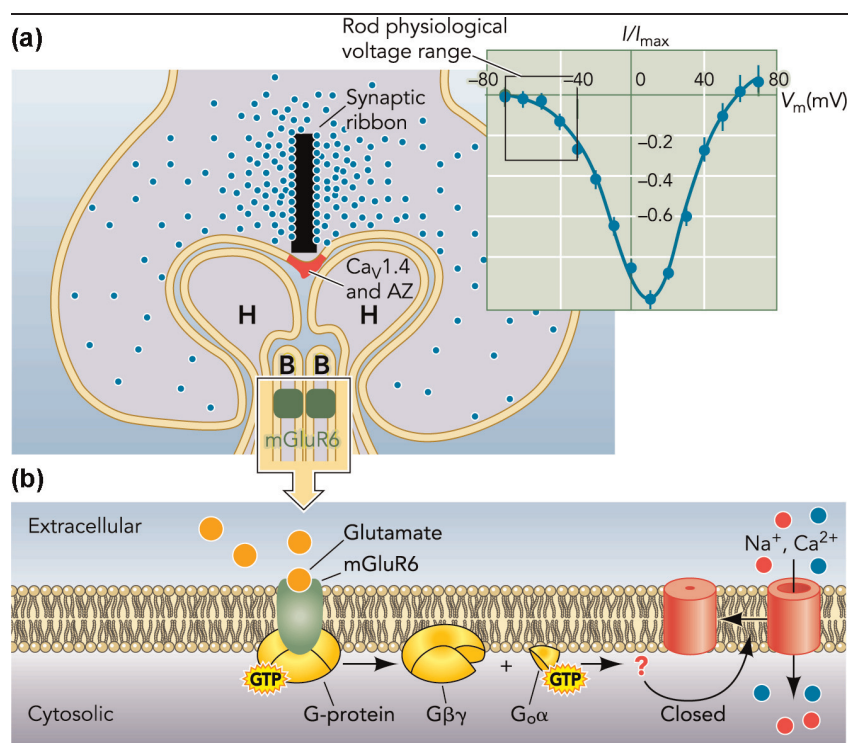

(a) The rod spherule is a specialized invaginating structure where the dendrites of horizontal $(\mathrm{H})$ and rod bipolar $(\mathrm{B})$ cells are apposed to glutamate release sites controlled by a synaptic ribbon. $\mathrm{Ca}^{2+}$ channels (Cavl.4) located near the active zone (AZ) allow the continuous release of glutamatergic vesicles in darkness. In 'On' rod bipolar cells, glutamate is sensed by metabotropic glutamate receptor type 6 (mGluR6) receptors located near the mouth of the invagination. Inset: Release of glutamate is dependent on $\mathrm{Ca}^{2+}$ influx through $\mathrm{Ca}^{2+}$ channels, which is graded by voltage over the physiological range. (b) The signaling cascade in rod bipolar cell dendrites is poorly characterized. mGluR6 activation leads to the activation of $G_{\circ} \alpha$, which through unknown mechanisms leads to the closure of nonselective cation channels, which may be in part TRPMI (transient receptor potential cation channel, melastatin family, member I). The lightevoked reduction in glutamate release relieves activity in this cascade and opens cation channels leading to membrane depolarization. Reprinted with permission from Physiology [32]. Copyright 2007, The American Physiological Society.
Through a series of unknown steps, the activity of this pathway leads to the closure of transduction channels, part of which may consist of TRPM1 [24,25], a member of the TRPM family of transient receptor potential (TRP) ion channels. Recent physiological evidence indicates that the properties of these channels are similar to those of other TRP channels-they can, for example, be gated by TRPV1 agonists [26]. Since postsynaptic saturation sets the position of the nonlinear threshold [23], elucidating the remaining transduction components will be key to identifying the components that set the level of synaptic saturation.

While the properties of signaling in the rod photoreceptors and rod bipolar cells have received much attention, other mechanisms downstream also play key roles in improving the fidelity of the single-photon response. For example, signals in AII amacrine cells are boosted by multivesicular release at the rod bipolar cellto-AII amacrine cell synapse, increasing the discrimination of the single-photon responses from synaptic noise [27]. Furthermore, AII amacrine cells create an electrically coupled network that may suppress synaptic noise [28]. This network is formed by gap junctions consisting of connexin 36 and is critical for the transmission of high-sensitivity signals to ganglion cells [29] by means of efficient signal transmission to cone bipolar cells [30].

\section{Future directions}

Over the past decade, significant advances have been made that have helped us understand how signals are preserved and noise is eliminated in the rod circuitry in order to maximize the detection of the single-photon response. However, several key issues remain. For example, what type of noise is limiting detection? Is it the discrete noise due to thermal activation of rhodop$\sin$, or the continuous noise produced by spontaneous PDE activation? In principle, either discrete or continuous noise could limit light detection by generating false-positive signals. Mechanisms such as the thresholdlike nonlinearity at the rod-to-rod bipolar synapse may eliminate much of the rod noise, but the identification of the molecular mechanism that is responsible will require the elucidation of the mGluR6 signaling cascade in the rod bipolar dendrites.

One other area of future investigation will be the identification and characterization of the retinal pathways that carry rod signals to ganglion cells. While the rod bipolar pathway may function predominantly near absolute threshold, it saturates at light levels where the rods are not saturated. Under these conditions, rod signals may use alternative rod pathways to relay signals. 
These include the rod-cone pathway [6] and the rod Off pathway [31], which are believed to relay signals for mesopic vision. The threshold and dynamic range of each pathway for relaying rod signals to ganglion cells remain to be determined.

\section{Abbreviations}

CaBP4, calcium-binding protein 4; cGMP, cyclic guanosine monophosphate; mGluR6, metabotropic glutamate receptor type 6; PDE, phosphodiesterase; RGSs, regulators of G-protein signaling; TRP, transient receptor potential; TRPM1, transient receptor potential cation channel, melastatin family, member 1; TRPV1, transient receptor potential cation channel, vallinoid family, member 1 .

\section{Competing interests}

The authors declare that they have no competing interests.

\section{Acknowledgments}

The authors acknowledge the support of National Institutes of Health grants EY-17606 (APS) and EY01844 (GLF) and a research grant from the Karl Kirschgessner Foundation (APS).

\section{References}

I. Hecht S, Schlaer S, Pirenne MH: Energy, quanta, and vision. J Gen Physiol 1942, 25:819-40.

2. van der Velden HA: The number of quanta necessary for the perception of light in the human eye. Opthalmologica 1946, I I I:32|-3|.

3. Barlow HB, LevickWR, Yoon M: Responses to single quanta of light in retinal ganglion cells of the cat. Vision Res 1971, 3:87-I0I.

4. Schneeweis DM, Schnapf JL: Photovoltage of rods and cones in the macaque retina. Science 1995, 268:1053-6.

5. Dacheux RF, Raviola E: The rod pathway in the rabbit retina: a depolarizing bipolar and amacrine cell. J Neurosci 1986, 6: $33 \mid-45$.

6. Smith RG, Freed MA, Sterling P: Microcircuitry of the darkadapted cat retina: functional architecture of the rod-cone network. J Neurosci 1986, 6:3505-17.

7. Burns ME, Mendez A, Chen J, Baylor DA: Dynamics of cyclic GMP synthesis in retinal rods. Neuron 2002, 36:81-91.

FI000 Factor 3.0 Recommended

Evaluated by Roger Hardie 18 Oct 2002

8. Mendez A, Burns ME, Sokal I, Dizhoor AM, Baehr W, Palczewski K, Baylor DA, Chen J: Role of guanylate cyclase-activating proteins (GCAPs) in setting the flash sensitivity of rod photoreceptors. Proc Natl Acad Sci U S A 200I, 98:9948-53.

FI000 Factor 3.0 Recommended

Evaluated by Roger Hardie 17 Sept 200I

9. Chen J, Makino CL, Peachey NS, Baylor DA, Simon MI: Mechanisms of rhodopsin inactivation in vivo as revealed by a COOHterminal truncation mutant. Science 1995, 267:374-7.

10. Mendez A, Burns ME, Roca A, Lem J, Wu LW, Simon MI, Baylor DA, Chen J: Rapid and reproducible deactivation of rhodopsin requires multiple phosphorylation sites. Neuron 2000, 28:15364.
II. Xu J, Dodd RL, Makino CL, Simon MI, Baylor DA, Chen J: Prolonged photoresponses in transgenic mouse rods lacking arrestin. Nature 1997, 389:505-9.

12. Chen CK, Burns ME, He W, Wensel TG, Baylor DA, Simon MI: Slowed recovery of rod photoresponse in mice lacking the GTPase accelerating protein RGS9-I. Nature 2000, 403: 557-60.

13. He W, Cowan CW, Wensel TG: RGS9, a GTPase accelerator for phototransduction. Neuron 1998, 20:95-102.

14. Okawa H, Sampath AP, Laughlin SB, Fain GL: ATP consumption by mammalian rod photoreceptors in darkness and in light. Curr Biol 2008, 18:1917-21.

FI000 Factor 3.0 Recommended

Evaluated by Roger Hardie 10 Feb 2009

15. Morgans CW, Bayley PR, Oesch NW, Ren G, Akileswaran L, Taylor WR: Photoreceptor calcium channels: insight from night blindness. Vis Neurosci 2005, 22:56I-8.

16. Haeseleer F, Imanishi Y, Maeda T, Possin DE, Maeda A, Lee A, Rieke F, Palczewski K: Essential role of $\mathrm{Ca}^{2+}$-binding protein 4, a Cavl.4 channel regulator, in photoreceptor synaptic function. Nat Neurosci 2004, 7:1079-87.

FI000 Factor 4.8 Must Read

Evaluated by Annette Dolphin 04 Oct 2004, Gordon Fain 19 Nov 2004

17. Thoreson WB, Rabl K, Townes-Anderson E, Heidelberger R: A highly $\mathrm{Ca}^{2+}$-sensitive pool of vesicles contributes to linearity at the rod photoreceptor ribbon synapse. Neuron 2004, 42:595605.

FI000 Factor 3.0 Recommended Evaluated by Gordon Fain 23 July 2004

18. Baylor DA, Lamb TD, Yau KW: Responses of retinal rods to single photons. J Physiol 1979, 288:6/3-34.

19. Baylor DA, Matthews G, Yau KW: Two components of electrical dark noise in toad retinal rod outer segments. J Physiol 1980, 309:59|-62I.

20. Baylor DA, Nunn BJ, Schnapf JL: The photocurrent, noise and spectral sensitivity of rods of the monkey Macaca fascicularis. J Physiol 1984, 357:575-607.

21. van Rossum MC, Smith RG: Noise removal at the rod synapse of mammalian retina. Vis Neurosci 1998, I 5:809-2I.

22. Field GD, Rieke F: Nonlinear signal transfer from mouse rods to bipolar cells and implications for visual sensitivity. Neuron 2002, 34:773-85

FI000 Factor 9.0 Exceptional

Evaluated by Richard Masland 26 Sept 2003

23. Sampath AP, Rieke F: Selective transmission of single photon responses by saturation at the rod-to-rod bipolar synapse. Neuron 2004, 41:431-43.

FI000 Factor 3.0 Recommended Evaluated by Gordon Fain 0I June 2004

24. Bellone RR, Brooks SA, Sandmeyer L, Murphy BA, Forsyth G, Archer S, Bailey E, Grahn B: Differential gene expression of TRPMI, the potential cause of congenital stationary night blindness and coat spotting patterns (LP) in the Appaloosa horse (Equus caballus). Genetics 2008, I79:I86I-70.

25. Nakajima $Y$, Moriyama $M$, Hattori $M$, Minato $N$, Nakanishi S: Isolation of ON bipolar cell genes via hrGFP-coupled cell enrichment using the mGluR6 promoter. J Biochem 2009, | 45:8 I I-8.

26. Shen Y, Heimel JA, Kamermans M, Peachey NS, Gregg RG, Nawy S: A transient receptor potential-like channel mediates synaptic transmission in rod bipolar cells. J Neurosci 2009, 29:6088-93.

FI000 Factor 3.0 Recommended

Evaluated by Jeffrey Diamond 15 May 2009 
27. Singer JH, Lassova L, Vardi N, Diamond JS: Coordinated multivesicular release at a mammalian ribbon synapse. Nat Neurosci 2004, 7:826-33.

28. Dunn FA, Doan T, Sampath AP, Rieke F: Controlling the gain of rod-mediated signals in the Mammalian retina. J Neurosci 2006, 26:3959-70.

29. Deans MR, Volgyi B, Goodenough DA, Bloomfield SA, Paul DL: Connexin 36 is essential for transmission of rod-mediated visual signals in the mammalian retina. Neuron 2002, 36:703-12.

FI000 Factor 4.8 Must Read

Evaluated by Richard Masland 03 Jan 2003, Bruce Nicholson 26 Sept 2003
30. Veruki ML, Hartveit E: Electrical synapses mediate signal transmission in the rod pathway of the mammalian retina. J Neurosci 2002, 22:10558-66.

FI000 Factor 3.0 Recommended

Evaluated by Richard Masland 03 Jan 2003

31. Soucy E, Wang Y, Nirenberg S, Nathans J, Meister M: A novel signaling pathway from rod photoreceptors to ganglion cells in mammalian retina. Neuron 1998, 21:481-93.

32. Okawa H, Sampath AP: Optimization of single-photon response transmission at the rod-to-rod bipolar synapse. Physiology 2007, 22:279-86. 